\title{
Treatment of Weight Gain with Fluoxetine in Olanzapine- Treated Schizophrenic Outpatients
}

\author{
Juan R Bustillo*,', John Lauriello', Katherine Parker', Roger Hammond', Laura Rowland', Michael \\ Bogenschutz' and Samuel Keith' \\ 'Department of Psychiatry, University of New Mexico, Albuquerque, NM, USA
}

\begin{abstract}
Significant weight gain is a side effect associated with olanzapine treatment in some patients. We investigated the efficacy of high-dose fluoxetine as a weight-reducing agent for patients who develop early weight gain with olanzapine treatment. Patients that gained $\geqslant 3 \%$ of their baseline weight in the initial 8 weeks of olanzapine treatment $(n=31)$ were randomized to double-blind treatment with placebo or fluoxetine $(60 \mathrm{mg} / \mathrm{day})$. Clinical, weight, and weight-related measures were assessed. Fluoxetine failed to demonstrate weight-reducing effects (fluoxetine group: baseline mean $80.5 \mathrm{~kg}, \mathrm{SD}=19.1$, last mean $=83.5 \mathrm{~kg}, \mathrm{SD}=19.8$; placebo group: baseline mean $=77.1 \mathrm{~kg}$, $\mathrm{SD}=12.1$, last mean $=78.8 \mathrm{~kg}, \mathrm{SD}=10.6 ; \mathrm{F}=1.3 ; \mathrm{df}=1,18 ; p=0.3$ ). There were no differential effects in psychopathology, extrapyramidal side effects or weight-related measures between the placebo and fluoxetine groups. Serotonin reuptake inhibitors are probably not a practical option to counteract weight gain induced by atypical antipsychotics. Atypical-induced weight gain may result from mechanisms other than $5 \mathrm{HT}$ reuptake blockade.
\end{abstract}

Neuropsychopharmacology (2003) 28, 527-529. doi: I 0.1038/sj.npp. 1300089

Keywords: fluoxetine; olanzapine; weight gain; obesity; controlled trial; antipsychotic

\section{INTRODUCTION}

A consistent adverse effect of atypical antipsychotic agents is weight gain. Olanzapine is an efficacious antipsychotic medication, but like other atypical agents, olanzapine can induce significant weight gain $(3.5 \mathrm{~kg}$ in 10 weeks; Allison et $a l, 1999)$. Fluoxetine, a $5 \mathrm{HT}$ reuptake blocker, is an effective anorectic agent during the first few months of treatment (Goldstein et al, 1994). Since olanzapine-induced weight gain may in part be mediated by its 5HT blocking effects, we thought that fluoxetine might prove to be a particularly effective anorectic agent in olanzapine-treated patients. Furthermore, as the maximum rates of weight gain with olanzapine and weight loss with fluoxetine occur between 8 and 12 weeks with both treatments (Kinon et al, 2001; Goldstein et al, 1994), we hypothesized that early addition of fluoxetine might prevent olanzapine-induced weight gain.

*Correspondence: JR Bustillo, Department of Psychiatry, Research Division, 2400 Tucker NE, University of New Mexico, Albuquerque, NM 87|3I, USA, Tel: +I 505272 558I, Fax: +I 5052725572 , E-mail: jbustillo@salud.unm.edu

Received 21 May 2002; revised 8 October 2002; accepted 10 October 2002

Online publication: 14 October 2002 at http://www.acnp.org/citations/ Npp I01402407

Funded by an investigator initiated grant to JR Bustillo from Lilly Pharmaceutical Corporation, by a young Investigator Award to J Lauriello from N.A.R.S.A.D. and by NIH NCRR GCRC grant 5MOI RR00997.

\section{METHODS}

Subjects

Subjects were outpatients from the University of New Mexico-Health Sciences Center who met the following inclusion criteria: (1) DSM-IV schizophrenia or schizoaffective disorder confirmed with the SCID DSM-IV (First et $a l, 1995)$; (2) history of partial response or intolerability to a typical antipsychotic medication; (3) 18-60 years old. Exclusion criteria were: (1) neurological disorder or active substance abuse; (2) prior treatment with olanzapine or treatment with any atypical antipsychotic within the previous 4 weeks; (3) significant medical problems; (4) use of antidepressant or mood stabilizing agents within the previous 6 weeks; (5) history of manic episode.

\section{Protocol}

The design included two phases: phase 1 (4-8 weeks), during which olanzapine was started $(10 \mathrm{mg} /$ day) and the patient was followed weekly with the goal of prospectively documenting weight gain (this period of time was selected as long enough to identify patients beginning to gain weight while not reaching a plateau for most subjects); and phase 2, during which patients who had gained at least $3 \%$ over baseline weight during 2 consecutive weeks in phase 1 were randomized to double-blind treatment with fluoxetine $(60 \mathrm{mg} /$ day) or placebo for 4 months; these subjects were 
assessed weekly the first month and monthly thereafter. During the whole study patients remained on olanzapine $(5-20 \mathrm{mg} /$ day); the dosage was determined according to clinical response, with only one $5 \mathrm{mg} /$ day adjustment (increase or decrease) allowed during phase 2. Fluoxetine/ placebo dose followed a forced titration schedule to $60 \mathrm{mg} /$ day during the first week, but was allowed individually determined adjustments (range $20-60 \mathrm{mg} /$ day) to improve tolerance. The study was approved by the local IRB and subjects provided written informed consent.

\section{Outcome Measures and Analyses}

The primary outcome variable was weight, measured weekly with a calibrated hospital scale, in subjects while wearing their clothes but no shoes. Percent body fat (measured with bioelectrical impedance analysis), and $24 \mathrm{~h}$ recall of diet (Thompson and Byers, 1994) and activity (Lipid Research Clinics Physical Activity Questionnaire, 1997) using standardized questionnaires were assessed by a research nutritionist (KP). Clinical ratings (positive and negative symptom schedule (Kay et al, 1987), abnormal involuntary movement scale (Guy, 1976), Simpson-Angus scale (Simpson and Angus, 1970), Barnes Akathisia scale (Barnes, 1989), and Hamilton depression scale (Hamilton, 1960)) were completed by the treating research psychiatrist. Outcome measures were analyzed with 2 (time: randomization, last observation) by 2 (group: placebo, fluoxetine) mixed factorial ANOVAs with repeated measures on time, for patients that remained in phase 2 for at least 1 month.

Table I Mean (SDs) Nutritional and Clinical Variables in Olanzapine-Treated Schizophrenia Patients Randomized to Fluoxetine and Placebo

\begin{tabular}{|c|c|c|c|}
\hline & $\begin{array}{l}\text { Fluoxetine } \\
(n=15)\end{array}$ & $\begin{array}{l}\text { Placebo } \\
(n=15)\end{array}$ & Statistic \\
\hline \multicolumn{4}{|l|}{ Patient characteristics } \\
\hline Age (yrs) & $33(12)$ & $36(1 \mathrm{l})$ & $t(28)=0.63, p=0.54$ \\
\hline Male/female & $12 / 3$ & $12 / 3$ & Fisher's exact test, $p=1.0$ \\
\hline SES & $4.6(0.7)$ & $4.4(0.9)$ & $t(22)=0.49, p=0.63$ \\
\hline Ethnicity (white/black/hispanic) & $7 / 0 / 8$ & $8 / 2 / 5$ & $\chi^{2}(2)=2.76, p=0.25$ \\
\hline Schizophrenia/schizoaffective $\mathrm{dx}$ & $|4 /|$ & $|4 /|$ & Fisher's exact test, $p=1.0$ \\
\hline Global assessment of function & $46(7.6)$ & $43(11.2)$ & $t(16)=0.67, p=0.52$ \\
\hline BMI $\left(\mathrm{kg} / \mathrm{m}^{2}\right)$ & $27(5.8)$ & $25(4.6)$ & $t(28)=1.2, p=0.25$ \\
\hline Weight gain during phase I (kg) & $3.9(1.7)$ & $3.9(1.5)$ & $t(28)=0.17, p=0.87$ \\
\hline Time (weeks) length of phase I & $4.0(1.3)$ & $3.9(1.3)$ & $t(28)=0.42, p=0.68$ \\
\hline Olanzapine (mg) end of phase 2 & $15(4.8)$ & $15(4.2)$ & $t(28)=0.20, p=0.84$ \\
\hline \multicolumn{3}{|l|}{ Weight-related measures } & $F(d f), p$ \\
\hline \multicolumn{4}{|l|}{ Weight (kg) } \\
\hline Baseline & $80.5(19.1)$ & $77.1(12.1)$ & $1.3(1,18), 0.3$ \\
\hline Last & $83.5(19.8)$ & $78.8(10.6)$ & \\
\hline \multicolumn{4}{|l|}{ Percent body fat } \\
\hline Baseline & $23.7(10.7)$ & $22.7(11.0)$ & $1.0(1,18), 0.3$ \\
\hline Last & $24.8(10.7)$ & $24.5(10.4)$ & \\
\hline \multicolumn{4}{|l|}{ Activity level: I (low)-4 (high) } \\
\hline Baseline & $1.9(1.2)$ & $1.8(1.1)$ & $0.2(1,18), 0.7$ \\
\hline Last & $2.2(1.3)$ & $2.2(1.2)$ & \\
\hline \multicolumn{4}{|l|}{$24 \mathrm{~h}$ dietary intake (kcal) } \\
\hline Baseline & $2100(908)$ & $2099(749)$ & $0.6(1,18), 0.5$ \\
\hline Last & $2168(1055)$ & I785 (784) & \\
\hline \multicolumn{4}{|l|}{ Clinical symptoms } \\
\hline \multicolumn{4}{|l|}{ Positive Sx (PANSS) } \\
\hline Baseline & $14.6(5.2)$ & I5.| (7.0) & $0.1(1,18), 0.8$ \\
\hline Last & $14.9(5.9)$ & | $4.8(7.0)$ & \\
\hline \multicolumn{4}{|l|}{ Negative Sx (PANSS) } \\
\hline Baseline & $21.7(6.8)$ & $17.9(5.3)$ & $0.5(1,18), 0.5$ \\
\hline Last & $20.3(5.9)$ & $17.5(6.4)$ & \\
\hline \multicolumn{4}{|l|}{ Depressive $S x$ (HAM-D) } \\
\hline Baseline & $5.9(4.3)$ & $7.3(6.6)$ & $1.9(1,18), 0.2$ \\
\hline Last & $7.5(4.7)$ & $5.7(3.7)$ & \\
\hline \multicolumn{4}{|l|}{ Extrapyramidal symptoms } \\
\hline \multicolumn{4}{|l|}{ Parkinsonism (SAS) } \\
\hline Baseline & | $3.7(4.9)$ & $11.6(2.1)$ & $0.1(1,18), 0.8$ \\
\hline Last & $13.5(4.6)$ & I I.I (I.3) & \\
\hline \multicolumn{4}{|l|}{ Akathisia (BAS) } \\
\hline Baseline & $1.0(1.7$ & $0.5(0.9)$ & $0.2(1,18), 0.6$ \\
\hline Last & $0.9(1.6)$ & $0.1(0.5)$ & \\
\hline \multicolumn{4}{|l|}{ Tardive dyskinesia (AIMS) } \\
\hline Baseline & $0.9(1.0)$ & $0.8(1.5)$ & $0.4(1,18), 0.6$ \\
\hline Last & I.I (2.1) & $0.6(1.3)$ & \\
\hline
\end{tabular}




\section{RESULTS}

A total of 53 patients initiated olanzapine and, of these, 31 met weight gain criteria, 10 failed to do so, and 12 withdrew before the completion of phase 1 . Of these 12 subjects, eight did not return for follow-up after the first visit, two were hospitalized for psychotic exacerbation, and one patient died (cause unrelated to study medication). Of the 31 randomized subjects, 30 completed at least 1 month of double-blind treatment. The fluoxetine-treated $(n=15)$ and placebo-treated $(n=15)$ groups did not significantly differ in age, sex, ethnicity, socioeconomic status, schizophrenia/ schizoaffective diagnoses, global assessment of function, body mass index, weight gain during phase 1, length of phase 1 , and olanzapine dose at the end of phase 2 (see Table 1).

Table 1 shows the means (SD) at the beginning and end of the trial for the fluoxetine and placebo-treated groups for nutritional and clinical variables. There were no statistically significant effects of treatment for weight or any of the other variables. An analysis of completers of the 4 -month trial (fluoxetine $n=11$, placebo $n=9$ ) also failed to show any differences. Fluoxetine was generally well tolerated with no significant change in symptomatology for the whole group.

\section{DISCUSSION}

We prospectively identified schizophrenia patients who developed early weight gain while taking olanzapine, and assessed the efficacy of high-dose fluoxetine to prevent further weight gain in a placebo-controlled design. There was no evidence of a weight-reducing effect for fluoxetine: both groups continued to gain weight $(0.8 \mathrm{~kg} /$ month for fluoxetine and $0.2 \mathrm{~kg} /$ month for placebo) although at a lower rate than before fluoxetine/placebo were added (3.9 $\mathrm{kg} / \mathrm{month}$ for fluoxetine and $3.9 \mathrm{~kg} /$ month for placebo). This reduction in the rate of olanzapine-induced weight gain after the initial 2 months of treatment has been previously reported (Kinon et al, 2001). Although our sample size was small, this is unlikely to explain our negative findings because the fluoxetine-treated group gained somewhat more weight than the placebo-treated group (3 vs $1.7 \mathrm{~kg}$, respectively).

The anorectic effect of high-dose fluoxetine $(60 \mathrm{mg} /$ day $)$ has been demonstrated in clinically obese, nonpsychiatric outpatients (Goldstein et al, 1994). In that study, the rate of weight loss for the fluoxetine-treated group leveled off at $12-20$ weeks with an average loss of $5 \mathrm{~kg}$ (placebo $=2 \mathrm{~kg}$ ). Our negative findings could be related to the difference in populations studied. The fluoxetine dose we used (mean $=56 \mathrm{mg} /$ day, $\mathrm{SD}=11)$ and length of treatment $(14.4$ weeks, $\mathrm{SD}=11.8$ ) were comparable to the earlier study. In a study of overweight schizophrenic outpatients chronically treated with typical antipsychotics, D-fenfluramine, another 5HT reuptake inhibitor, had a limited effect in a 12 -week placebo-controlled trial: the D-fenfluramine-treated group had a greater weekly rate of weight loss than the placebo group, but the two groups did not differ in absolute weight loss (Goodall et al, 1988). Recently, simultaneous administration of fluoxetine $(20 \mathrm{mg} /$ day $)$ with olanzapine $(10 \mathrm{mg} /$ day), was also found to be ineffective to prevent weight-gain in first-episode schizophrenia (Poyurovsky et al, 2002).

In conclusion, serotonin reuptake blockers are probably not a practical option to counteract weight gain induced by atypical antipsychotics. Atypical-induced weight gain may result from mechanisms other than 5HT blockade (such as antihistaminergic properties). Weight-gain profiles of the various atypicals (Allison et al, 1999) are not linked to the drugs' serotonergic blocking properties (Pickar, 1995). For example ziprasodone and risperidone, both potent 5HT blockers are less likely to cause weigh-gain than drugs with lesser 5HT affinity, like olanzapine and clozapine. Strategies for weight gain prevention and reduction among the chronically mentally ill, are very much needed.

\section{REFERENCES}

Allison DB, Mentore JL, Heo M, Chandler LP, Cappelleri JC, Infante MC et al (1999). Antipsychotic-induced weight gain: a comprehensive research synthesis. Am J Psychiatry 156: 16861696.

Barnes TR (1989). A rating scale for drug-induced akathisia. $\mathrm{Br} \mathrm{J}$ Psychiatry 154: 672-676.

First MB, Spitzer RL, Gibbon M, Williams JBW (1995). Structured Clinical Interview for DSM-IV Axis I Disorders, Patient Edition (SCID-P), version. New York State Psychiatric Institute, Biometrics Research: New York.

Goldstein D, Rampey A, Enas G, Potvin J, Fludzinski L, Levine L (1994). Fluoxetine: a randomized clinical trial in the treatment of obesity. Int J Obes Relat Metab Disord 18: 129-135.

Goodall E, Oxtoby C, Richards R, Watkinson G, Brown D, Silverston $T$ (1988). A clinical trial of the efficacy and acceptability of d-fenfluramine in the treatment of neurolepticinduced obesity. Br J Psychiatry 153: 203-208.

Guy W (1976). ECDEU Assessment Manual for Psychopharmacology: Publication ADM 76-338. US Department of Health, Education and Welfare: Washington, DC. pp 534-537.

Hamilton M (1960). A rating scale for depression. J Neurol Neurosurg Psychiatry 23: 56-62.

Kay SR, Fiszbein A, Opler LA (1987). The positive and negative syndrome scale (PANSS) for schizophrenia. Schizophr Bull 13: 261-276.

Kinon BJ, Basson BR, Gilmore JA, Tollefson GD (2001). Long-term olanzapine treatment: weight change and weight-related health factors in schizophrenia. J Clin Psychiatry 62: 92-100.

Lipid Research Clinics Physical Activity Questionnaire (1997). Med Sci Sports Exercise 2: S59-61.

Pickar D (1995). Prospects for pharmacotherapy in schizophrenia. Lancet 345: 557-561.

Poyurovsky M, Pashinian A, Gil-Ad I, Maayan R, Schneidman M, Fuchs $C$ et al (2002). Olanzapine-induced weight-gain in patients with first episode schizophrenia: a double-blind, placebo controlled study of fluoxetine addition. Am J Psychiatry 159: 1058-1060.

Simpson GM, Angus JW (1970). A rating scale for extrapyramidal side-effects. Acta Psychiatr Scand 212(Suppl): 11-19.

Thompson FE, Byers T (1994). Dietary assessment resource manual. J Nutrition 124: 11S. 